\title{
Use of a Brief Screening Tool to Assess Intellectual Functioning in a Forensic Population
}

\author{
Andrew Donohue ${ }^{1, *}$, Jack Samuels ${ }^{2}$, Robert Thompson ${ }^{1}$, Clarence Watson ${ }^{1}$ and \\ Gerard Gallucci ${ }^{3}$
}

\author{
${ }^{1}$ Delaware Psychiatric Center, New Castle, DE, USA \\ ${ }^{2}$ Department of Psychiatry and Behavioral Sciences, The Johns Hopkins University School of Medicine, \\ Baltimore Maryland, USA \\ ${ }^{3}$ Delaware Division of Substance Abuse and Mental Health, New Castle, DE, USA
}

\begin{abstract}
Individuals with intellectual disability are over-represented in forensic settings, including jails, prisons and forensic psychiatric treatment units. Identification of intellectual disability is important in such settings, especially in light of the implications of intellectual disability in legal issues including competency to stand trial, criminal responsibility and capital sentencing. We examined the utility of a brief test of intelligence (PROFOKS), assessing knowledge of proverbs, fund of knowledge and similarities in a series of 29 inpatients residing in a forensic psychiatric unit. PROFOKS correlated strongly with performance on the Wechsler Abbreviated Scale of Intelligence (WASI), including the full scale, verbal and performance IQs and WASI subscales. The PROFOKS appears to be a useful screening tool in identifying intellectual disability in a forensic psychiatric population.
\end{abstract}

Keywords: Intellectual Disability, Assessment, Screening, Forensic, Evaluation, Brief, Tool, Instrument.

\section{INTRODUCTION}

It is important to identify cognitive impairment, including intellectual and developmental disability, in individuals undergoing assessment or treatment in forensic settings. Examples of forensic evaluations in which cognitive and intellectual abilities are relevant to the legal outcome of a case include assessment of: competency to stand trial [1-5], a defendant's state of mind at the time of an offense [6, 7], capacity for employment, treatment refusal [8], parental fitness [9], need for guardianship [10] and issues related to capitol punishment [11, 12]. Evaluation of intellectual abilities is essential for formulating an effective treatment plan [13] and in maximizing the effectiveness of competency restoration $[1,14,15]$. Because intellectual impairment, particularly when coupled with mental illness or substance abuse, is a risk factor for criminal recidivism [16], identification of intellectual impairment is useful in forensic assessment and treatment, with harm reduction as a goal.

Despite the fact that individuals with intellectual disabilities are common in forensic settings [17, 18], identification and quantification of these disabilities is often inadequate. An Australian study estimated that ten percent of young male prisoners met criteria for intellectual disability [19]. Despite this, screening for intellectual disabilities is uncommon in jail settings [20].

*Address correspondence to this author at the Delaware Psychiatric Center, 1906 Maryland Ave, Wilmington, DE 19805, USA; Tel: 302-778-6924;

Fax: 203-778-6901; E-mail: Andrew.Donohue@state.de.us
Forensic assessments can be extensive and can include psychological testing of intelligence, but a brief screening tool would also be useful. Traditional tests of intellectual disability tend to be lengthy, and may require a psychologist skilled in testing to administer [21-26]. Brief cognitive tests familiar to psychiatrists and other mental health professionals, including the Mini Mental State Examination (MMSE) [27] are inadequate for detecting intellectual disability in individuals with subnormal intelligence [28], and similar instruments such as the Montreal Cognitive Assessment (MOCA) [29] likely have little utility in this population. Other brief intelligence tests exist and have been used in the forensic setting, such as the Kaufman Brief Intelligence Test (K-BIT) [30]. K-BIT is a relatively brief tool, but it cannot easily be employed as part of a routine mental status examination because it requires 20 minutes to administer, specific test materials and some expertise in psychological testing. Given the lengthy nature of available tests of intellectual abilities, and the lack of utility of screening tools such as the MMSE, the availability of a brief screening tool for the assessment of intellectual disability in forensic settings would be useful.

PROFOKS is a brief test of intelligence [31]. It is an easily administered test that evaluates an individual's ability to interpret proverbs, tests fund of knowledge and understanding of similarities. PROFOKS has been shown to be an effective tool in evaluating cognitive impairment in community and clinical samples of individuals with intellectual disability [31]. This study 
seeks to determine if the PROFOKS is a valid screening instrument for the identification and gross quantification of intellectual disabilities in a forensic setting.

\section{METHOD}

This study was approved by Delaware's Division of Health and Social Services' Institutional Review Board. Patients at the Delaware Psychiatric Center's inpatient forensic unit were informed of the foreseeable risks and benefits of participation and asked to participate in the study, with the understanding that participation did not affect their treatment plan or length of stay at the hospital. Prospective participants were informed that they could withdraw from the study at any time and this too would not alter treatment or duration of hospitalization. A written informed consent document was utilized, in conjunction with verbal explanation. Participants were informally assessed for the ability to provide consent and given the opportunity to ask questions at the onset and throughout the study.

\section{PARTICIPANTS}

The individuals who participated in this study were all committed to the Delaware Psychiatric Center's forensic unit either because they were adjudicated incompetent to stand trial, found guilty but mentally ill, found not guilty by reason of insanity or were prisoners who were civilly committed to the hospital for treatment. A series of 29 participants were chosen randomly from the inpatient census of 42 patients over a period of six months.

Of the 29 participants, diagnostic information was available on 28 subjects. One subject was diagnosed with intellectual disability. Eleven subjects had a primary diagnosis of a psychotic disorder, eight had a mood disorder, five had either a personality disorder, addictive disorder or an impulse control disorder, two had an organic brain dysfunction, one had Asperger's Disorder (without intellectual disability) and one had Pervasive Developmental Disorder, Not otherwise Specified with Mild Intellectual Disability. Axis V Global Assessment of Functioning (GAF) score results included a range of 25 to 65 with a mean of 44 .

The sample was comprised of $79 \%$ males, and $21 \%$ females. Participants were from 20 to 62 years of age. Median age was 37.2 years and $96 \%$ were less than 56 years of age. Most had a high school diploma. The average educational level was 12.6 years of completed schooling. $11 \%$ were married, $70 \%$ were single and $19 \%$ were divorced.

\section{MEASURES}

\section{Wechsler Abbreviated Scale of Intelligence}

The WASI is a brief test that measures intellectual abilities, requiring approximately 30 minutes to administer. The WASI consists of four subtests: Vocabulary, Similarities, Block Design, and Matrix Reasoning. The four-subtests are used to compute Verbal IQ (VIQ), Performance IQ (PIQ), and Full Scale IQ (FSIQ) scores. This scale has demonstrated validity as a measure of intellectual abilities in samples of psychiatric inpatients and in other samples [32, 33].

\section{PROFOKS}

The PROFOKS scale assesses knowledge of proverbs, fund of knowledge and similarities. Subjects can score between zero (a perfect score) and 16 points (no correct answers). See PROFOKS instrument (Figure 1). On PROFOKS, a lower score represents superior performance; zero is a perfect score and 16 is the worst possible score.

\section{Procedure}

After consent was obtained, we administered the PROFOKS and the Wechsler Abbreviated Scale of Intelligence (WASI) to a series of 29 inpatients at the Mitchell Forensic unit of the Delaware Psychiatric Center. The tests were given by staff trained in administering psychological tests. Tests were completed within one testing session.

PROKOKS scores were obtained, in addition to WASI Verbal IQ, Performance IQ, Full Scale IQ primary scale scores, along with Vocabulary, Block Design, Similarities and Matrix subscale scores.

\section{DATA ANALYSIS}

We correlated PROFOKS score to Verbal, Performance and Full Scale $I Q$ as well as to Vocabulary, Block Design, Similarities and Matrix subscales of the WASI. We also correlated PROFOKS score with age and Axis $V$ Global Assessment of Functioning (GAF) score.

\section{RESULTS}

PROFOKS scores varied from 0 to 13 , with a mean score of 3.3 and a standard deviation of 3.3. 20 


\section{PROFOKS}

FUND OF KNOWEDGE

1. Who is the president of the United States?

2. Can you name the last five presidents, starting with the current president?

3. Can you name five big cities in the United States?

4. What is the capitol of (state of residence)

Fund of Knowledge Subtotal

SIMILARITIES

1. How is an apple like a banana?

\section{Complete}

2. How is an eye like an ear?

3. How is a telephone like a letter?

Similarities Subtotal

PROVERBS - Ask the subject, "What do people mean when they say...

1. "Don't cry over spilled milk?" (or, "The horse is out of the barn?")

2. "You can't tell a book by its cover?" (or, "All that shines is not Gold?")

3. "Don't count your chickens before they hatch?" (or, "Look before you leap?")

Proverbs Subtotal

PROFOKS TOTAL SCORE

\section{Figure 1:}

participants (69\%) achieved scores of three or below on PROFOKS. Two subjects (7\%) scored greater than ten. The two subjects with scores greater than ten also scored less than 70 full scale IQ on the WASI. Figure 2 shows the relationship between PROFOKS and Full Scale IQ:
0

$\begin{array}{cc}\text { Correct } & \text { Incorrect } \\ 0 & 1 \\ 0 & 1 \\ 0 & 1 \\ 0 & 1\end{array}$

Remote

Incorrect

0

0

Complete

0

Remote

No Sense

0

0
The PROFOKS score correlated with WAIS Verbal $I Q$, Performance IQ and Full Scale IQ. WAIS subscales including the Vocabulary, Block Design, Similarities and Matrix subscales also correlated strongly with PROFOKS. Age and Axis $V$ were not related to performance on PROFOKS (Table 1). The correlation

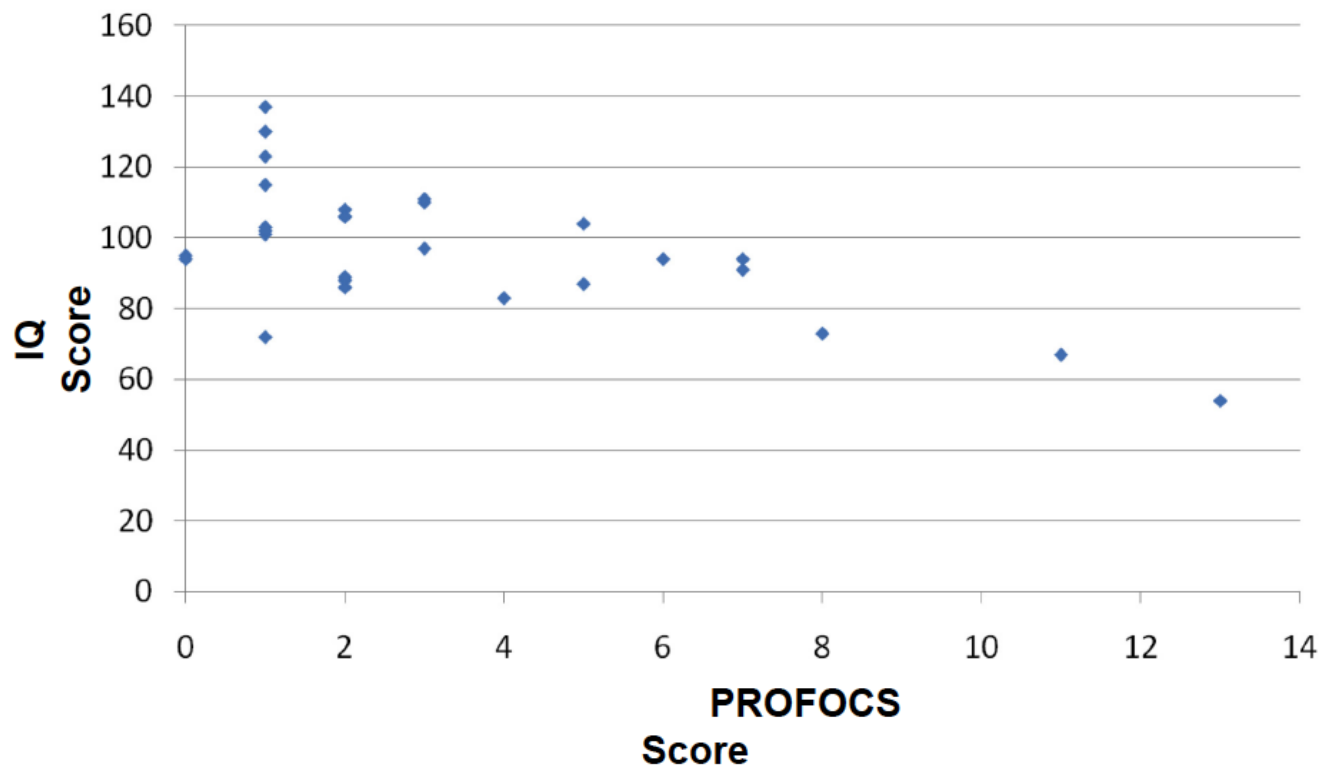

Figure 2: Performance on the PROFOKS: WASI full Scale IQ by PROFOKS Score. 
was stronger for Verbal than for performance IQ and stronger for the Vocabulary and Similarity subscales than for the Block Design and Matrix Subscales.

Table 1: Correlation of PROFOKS to other Measures

\begin{tabular}{|c|c|c|}
\hline & $\begin{array}{c}\text { Pearson Correlation } \\
\text { Coefficient (r) }\end{array}$ & Sig \\
\hline \hline Verbal IQ & -0.694 & 0.000 \\
\hline Performance IQ & -0.492 & 0.007 \\
\hline Full Scale IQ & -0.653 & 0.000 \\
\hline Subscale Vocabulary & -0.760 & 0.000 \\
\hline Subscale Block Design & -0.431 & 0.019 \\
\hline Subscale Similarities & -0.666 & 0.000 \\
\hline Matrix & -0.478 & 0.010 \\
\hline Age & 0.058 & 0.771 \\
\hline Axis V & -0.097 & 0.712 \\
\hline
\end{tabular}

\section{DISCUSSION}

This study utilized a small sample of forensic psychiatric patients. Within this sample, PROFOKS performance correlated with performance on WAIS Full scale IQ, Verbal and Performance IQ and WAIS subscales. A relatively high percentage $(7 \%)$ of this small sample of participants had Iow IQ as measured by WASI, compared to the typical rate of intellectual disabilities in community samples of approximately $1 \%$ [34]. This result is not inconsistent with data suggesting higher rates of intellectual disabilities in forensic settings and a forensic psychiatric hospital may be expected to have an especially elevated proportion of patients with low IQ.

Malingering is an issue of interest in forensic settings; we did not specifically assess participants to determine this behavior. Neither PROFOKS nor WASI are effective tools for screening for malingering and neither is recommended for this purpose. One participant's diagnosis included a rule-out diagnosis of malingering. Malingering, if present, could have been expected to reduce overall scores and affect the consistency of responses among participants and thus could have reduced the concordance of WAIS and PROFOKS scores. The participant with a diagnosis of possible malingering did not perform poorly on either PROFOKS or WASI and no participants demonstrated inconsistent performance across the measures, thus suggesting that Malingering did not confound the study's results.
This study's demonstrable correlation between PROFOKS scores and WASI scales and subscale results, along with previous studies showing that PROFOKS performance correlates with intellectual disabilities in community and clinical samples, indicate that the PROFOKS instrument could prove to be useful in forensic settings. Because PROFOKS is quick and easy to administer, and does not require specialized psychological testing expertise, it could be a useful tool for forensic psychiatrists, either as a gross assessment of intellectual abilities or as a screening instrument to determine which patients would benefit from more intensive psychological testing. This instrument is not sufficient to supplant psychological testing for assessing intellectual ability, and it does not assess adaptive functioning. To further assess the correlation between PROFOKS and WASI, additional study with a larger sample size would be useful. Further study is necessary to determine if performance on PROFOKS can be useful for quantifying intellectual impairment beyond its utility as a screening tool.

\section{REFERENCES}

[1] Mossman D. Predicting restorability of incompetent criminal defendants. J Am Acad Psychiatry Law 2007; 35(1): 34-43.

[2] Mossman D, Noffsinger SG, Ash P, et al. AAPL Practice Guideline for the forensic psychiatric evaluation of competence to stand trial. American Academy of Psychiatry and the Law. J Am Acad Psychiatry Law 2007; 35(4 Suppl): S3-72.

[3] Warren JI, Aaron J, Ryan E, Chauhan P, DuVal J. Correlates of adjudicative competence among psychiatrically impaired juveniles. J Am Acad Psychiatry Law 2003; 31(3): 299-309.

[4] Reich J, Wells J. Defendants with repeated competency evaluations. J Nerv Ment Dis 1986; 174(2): 120-2. http://dx.doi.org/10.1097/00005053-198602000-00009

[5] Miller RD, Germain EJ. The retrospective evaluation of competency to stand trial. Int J Law Psychiatry 1988; 11(2): 113-25.

http://dx.doi.org/10.1016/0160-2527(88)90025-8

[6] Giorgi-Guarnieri D, Janofsky J, Keram E, et al. AAPL practice guideline for forensic psychiatric evaluation of defendants raising the insanity defense. American Academy of Psychiatry and the Law. American Academy of Psychiatry and the Law. Am Acad Psychiatry Law 2002; 30(2 Suppl): S3-40.

[7] Kunjukrishnan $R$, Varan LR. Interface between mental subnormality and law--a review. Psychiatr J Univ Ott 1989; 14(3): 439-52.

[8] Appelbaum PS, Grisso T. Assessing patients' capacities to consent to treatment. N Engl J Med 1988; 319(25): 1635-8. http://dx.doi.org/10.1056/NEJM198812223192504

[9] Smith SM, Kunjukrishnan R. Medicolegal aspects of mental retardation. Psychiatr Clin North Am 1986 Dec; 9(4): 699-12.

[10] Stancliffe RJ, Abery BH, Springborg H, Elkin S. Substitute decision-making and personal control: implications for selfdetermination. Ment Retard 2000; 38(5): 407-21.

http://dx.doi.org/10.1352/0047-

6765(2000)038<0407:SDAPCl>2.0.CO;2

[11] Atkins v Virginia, 536 US 3042002. 
[12] Appelbaum PS. Law \& psychiatry: mental retardation and the death penalty: after Atkins. Psychiatr Serv 2009; 60(10): 1295-7. http://dx.doi.org/10.1176/appi.ps.60.10.1295

[13] Torrey WC. Psychiatric care of adults with developmental disabilities and mental illness in the community. Commun Ment Health J 1993; 29(5): 461-76; discussion 477-81. http://dx.doi.org/10.1007/BF00754415

[14] Wall BW, Krupp BH, Guilmette T. Restoration of competency to stand trial: a training program for persons with mental retardation. J Am Acad Psychiatry Law 2003; 31(2): 189-201.

[15] Stoops R, Hess J, Scott T, et al. Training competency to stand trial in an individual with intellectual disability and behavioral health concerns. Mental Health Aspects of Developmental Disabilities 2007; 10(2): 47-52.

[16] Holland T, Clare IC, Mukhopadhyay T. Prevalence of criminal offending by men and women with intellectual disability and the characteristics of offenders: implications for research and service development. J Intellect Disabil Res 2002; 46(Suppl 1): $6-20$. http://dx.doi.org/10.1046/j.1365-2788.2002.00001.x

[17] Lindsay, WR, Taylor JL. A selective review of research on offenders with developmental disabilities: Assessment and treatment. Clin Psychol Psychother 2005; 12: 201-14. http://dx.doi.org/10.1002/cpp.450

[18] Lindsay WR, Sturmey P, Taylor JL. Natural History and Theories of Offending in People with Developmental Disabilities. Offenders with Developmental Disabilities, Chichester: Wiley 2004; pp. 3-22. http://dx.doi.org/10.1002/9780470713440.ch1

[19] Harrington V. Assessing the prevalence of intellectual disability among young male prisoners. J Intellect Disabil Res 2009; 53(5): 397-410. Epub 2009 Feb 4.

http://dx.doi.org/10.1111/j.1365-2788.2008.01150.x

[20] Scheyett A, Vaughn J, Taylor M, Parish S. Are we there yet? Screening processes for intellectual and developmental disabilities in jail settings. Intellect Dev Disabil 2009; 47(1): 13-23.

http://dx.doi.org/10.1352/2009.47:13-23

[21] Kvaal SA, Wygonik E, Spanos A, Landsberger S. A revalidation of the Thurstone Test of Mental Alertness as a brief measure of intelligence through comparison with the Wechsler Adult Intelligence Scale-III. Psychol Rep 2001; 88(2): 581-6.

http://dx.doi.org/10.2466/pr0.2001.88.2.581

[22] Klimczak NC, Bradford KA, Burright RG, Donovick PJ. KFAST and WRAT-3: are they really different? Clin Neuropsychol 2000; 14(1): 135-8. http://dx.doi.org/10.1076/1385-4046(200002)14:1;1-8;FT135

[23] Bowers TL, Pantle ML. Shipley institute for living scale and the Kaufman Brief Intelligence Test as screening instruments for intelligence. Assessment 1998; 5(2): 187-95. http://dx.doi.org/10.1177/107319119800500209
[24] Axelrod BN, Naugle RI. Evaluation of two brief and reliable estimates of the WAIS-R. Int J Neurosci 1998; 94(1-2): 8591 http://dx.doi.org/10.3109/00207459808986441

[25] Edinger JD, Shipley RH, Watkins CE Jr, Hammett EB. Validity of the Wonderlic Personnel Test as a brief IQ measure in psychiatric patients. J Consult Clin Psychol 1985; 53(6): 937-9. http://dx.doi.org/10.1037/0022-006X.53.6.937

[26] Hafner JL, Corotto LV, Curnutt RH. The development of a WAIS short form for clinical populations. J Clin Psychol 1978; 34(4): 935-7. http://dx.doi.org/10.1002/1097-4679(197810)34:4<935::AIDJCLP2270340422>3.0.CO;2-M

[27] Folstein MF, Robins LN, Helzer JE. The Mini-Mental State Examination. Arch Gen Psychiatry 1983; 40(7): 812. http://dx.doi.org/10.1001/archpsyc.1983.01790060110016

[28] Myers BA. The Mini Mental State in those with developmental disabilities. J Nerv Ment Dis 1987; 175(2): 859. http://dx.doi.org/10.1097/00005053-198702000-00003

[29] Nasreddine ZS, Phillips NA, Bédirian V, et al. The Montrea Cognitive Assessment, MoCA: a brief screening tool for mild cognitive impairment. J Am Geriatr Soc 2005; 53(4): 695-9. http://dx.doi.org/10.1111/j.1532-5415.2005.53221.x

[30] Klinge V, Dorsey J. Correlates of the Woodcock-Johnson Reading Comprehension and Kaufman Brief Intelligence Test in a forensic psychiatric population. J Clin Psychol 1993; 49(4): 593-8. http://dx.doi.org/10.1002/1097-4679(199307)49:4<593::AIDJCLP2270490418>3.0.CO;2-H

[31] Gallucci G, Hackerman F, Nestadt G, Rabins P, Eaton W, Samuels J. Cognitive impairment in the Non-elderly: Validation of a new tool to assess intellectual disability in community and clinical populations. J Dev Phys Disabil 2007; 19: $519-530$. http://dx.doi.org/10.1007/s10882-007-9068-2

[32] Hays JR, Reas DL, Shaw JB. Concurrent validity of the Wechsler abbreviated scale of intelligence and the Kaufman brief intelligence test among psychiatric inpatients. Psychol Rep 2002; 90(2): 355-9. http://dx.doi.org/10.2466/pr0.2002.90.2.355

[33] Raggio DJ, Scattone D, May W. Relationship of the Kaufman Brief Intelligence Test-Second Edition and the Wechsler Abbreviated Scale of Intelligence in children referred for ADHD. Psychol Rep 2010; 106(2): 513-8. http://dx.doi.org/10.2466/pr0.106.2.513-518

[34] Maulik P, Mascarenhas M, Mathers C, Dua T, Saxena S. Prevalence of intellectual disability: A meta-analysis of population-based studies. Res Dev Disabilit 2011; 32: 41936.

http://dx.doi.org/10.1016/j.ridd.2010.12.018

Received on 16-12-2013

\section{DOI: http://dx.doi.org/10.6000/2292-2598.2014.02.01.7}

(C) 2014 Donohue et al.; Licensee Lifescience Global.

This is an open access article licensed under the terms of the Creative Commons Attribution Non-Commercial License (http://creativecommons.org/licenses/by-nc/3.0/) which permits unrestricted, non-commercial use, distribution and reproduction in any medium, provided the work is properly cited. 